МЕЛЬНИКОВ Сергей Леонидович - кандидат педагогических наук, профессор Брянского государственного университета им. академика И.Г. Петровского (241023, Россия, г. Брянск, ул. Бежицкая, 14)

ЛИФАНОВА Татьяна Евгеньевна - кандидат педагогических наук, доцент кафедры социологии и социальной работы Брянского государственного университета им. академика И.Г. Петровского (241023, Россия, г. Брянск, ул. Бежицкая, 14)

ШИЛИНА Светлана Александровна - доктор социологических наук, профессор кафедры социологии и социальной работы Брянского государственного университета им. академика И.Г. Петровского (241023, Россия, г. Брянск, ул. Бежицкая, 14; supershili2012@yandex.ru)

\title{
УПРАВЛЕНИЕ РИСКАМИ ИНКЛЮЗИВНОГО ОБРАЗОВАНИЯ
}

\begin{abstract}
Аннотация. В статье рассматриваются актуальные вопросы отношения молодежи (студентов и школьников старших классов) к лицам с ограниченными возможностями здоровья. Авторы представлют результаты социологического исследования, в котором выявлено, какие реперные точки существуют при внедрении инклюзивного образования в России. Авторы проанализировали вопросы, которые необходимо решить, чтобы обеспечить лояльность по отношению лицам с ограниченными возможностями здоровья в современном обществе. Многое зависит от управленческих решений по обеспечению доступной среды для данной категории граждан. Чтобы избежать рисков во внедрении инклюзивного образования, необходимы совместные усилия общества и государства. Социальная политика должна быть направлена на то, чтобы облегчить вхождение лиц с ограниченными возможностями здоровья в социум. Необходимы меры, создающие толерантное отношение к таким людям, а также благоприятные условия для их существования в городской среде современных мегаполисов, что, несомненно, является насущной проблемой нашего государства.
\end{abstract}

Ключевые слова: инклюзивное образование, люди с ограниченными возможностями здоровья, инвалиды, риски, управление, COVID-19, общество

A ктуальность обращения к вопросам управления рисками инклюзивного образования несомненна. В свете реформирования образования [Киричек 2017; 2018; Мамедов 2018], осложненного переходом на дистанционное обучение [Байдакова, Киричек 2013] в определенные моменты, связанные с санэпидемиологической обстановкой в мире и нашей стране [Шилина и др. 2021; Мамедов 2021; Голенкова, Свердлова 2021], актуальным является обращение к внедрению инклюзивного образования [Ковалева, Сычева 2019; Шилина, Боброва С.А., Лученинова 2019; Шилина, Федорова 2019], когда предполагается создание доступной среды для лиц с ограниченными возможностями здоровья [Сычева, Белова 2019; Лифанова, Сычева 2019; Ковалева, Касацкая, Ковалева 2019]. Вступление в информационную эпоху требует от обучаемых и обучающих особых навыков, умений и знаний [Волнистая, Мамедов 2018; Киричек 2016; Мамедов 2016], что означает возникновение рисков в получении образования для лиц с ограниченными возможностями здоровья [Голенкова 2014]. Готовы ли учебные заведения к тому, чтобы такие люди имели равный доступ к образовательным услугам в обычной школе, колледже, вузе? Как будут относиться к лицам с ограниченными возможностями здоровья в классе, студенческой группе? Эти вопросы требуют пристального внимания исследователей-социологов [Воронов, Пимахова, Шилина 2018; Гезалов, Коркия, Мамедов 2018].

В связи с этим нами проведено социологическое исследование на базе лаборатории социологии и социальных технологий Брянского государственного университета имени академика И.Г. Петровского с 13.04.2021 по 08.05.2021. 
В анкетировании участвовали учащиеся школ города Брянска $(27,06 \%$ всех респондентов) и студенты (72,94\% всех 85 респондентов). Возраст респондентов - от 13 до 35 лет, по половой принадлежности респонденты распределились следующим образом: 30,59\% юношей и 69,41\% девушек.

При ответе на 1-й вопрос анкеты, который был открытым: «Ваше понимание выражения “лица с ограниченными возможностями здоровья”?» -предполагалось, что напишут «инвалиды».

Но предположение не оправдалось: такое определение встретилось только у $15,29 \%$ респондентов. Причем многие добавили комментарии вроде: «овощи», «с психическими или физическими осложнениями», «люди, которые по каким-либо причинам не способны выполнять определенный перечень функций».

Среди них 15,38\% респондентов мужского пола и 84,62\% женского; 23,08\% составили школьники, 76,92\% - студенты. Распределение респондентов по возрасту представлено в диаграмме на рис. 1.

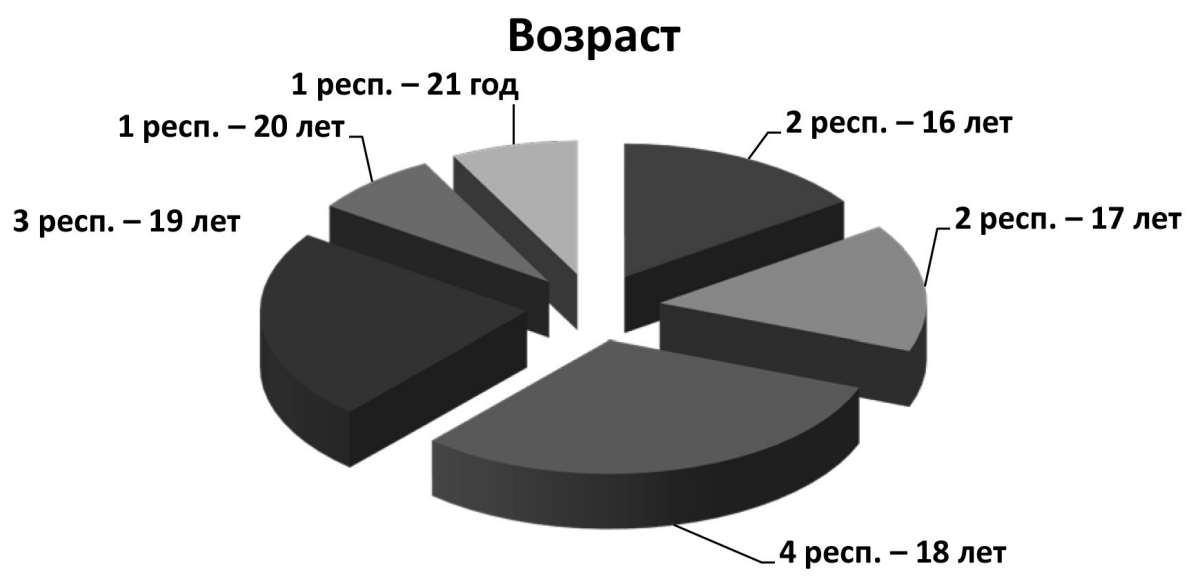

Рисунок 1. Распределение ответов респондентов на вопрос: «Ваше понимание выражения “лица с ограниченными возможностями здоровья”?» в зависимости от возраста

Нами была также выделена группа с ответами, в которых говорилось о лицах с ограниченными возможностями как о людях, имеющих физические недостатки. Таких анкет оказалось $23,53 \%$ общего числа респондентов.

Респонденты считают, что лица с ограниченными возможностями - это те, кому требуется помощь при передвижении. Из всех ответивших таким образом $45 \%$ составили респонденты женского пола и 55\% мужского. Среди респондентов $35 \%$ составляют школьники и $65 \%$ - студенты.

К данным ответам примыкают те 8,24\%, в которых респонденты обозначили понятие «лица с ограниченными возможностями здоровья» через отношение к деятельности - возможность/невозможность ее осушествления.

Приведем примеры: «Это люди, которые по стечению обстоятельств не могут выполнять трудовую активность в полной мере», «люди, которые не как все; люди, которые не могут выполнять какую-либо деятельность наравне со всеми».

Также выделен блок, в котором упомянуты не только физические, но и психические и/или умственные недостатки. Анкет с этими ответами 11,76\% (80\% 
респондентов женского пола и $20 \%$ респондентов мужского пола). Приведем пример: «Это люди, имеющие недостатки в своем физическом и/или психическом развитии».

В ответах 14,12\% общего числа респондентов найдено понятие здоровья/ болезни. Среди них 33,33\% респондентов мужского пола и 66,67\% респондентов женского пола. Возрастное распределение представлено в диаграмме на рис. 2.

В ответах 5,88\% общего числа респондентов основным было понятие нормы: «Люди, для которых существуют ограничения для нормального существования», «люди, отличающиеся от понятия нормы».

9,41\% респондентов говорили о необходимости посторонней помощи лицам с ограниченными возможностями. Приведем примеры формулировок ответов: «Это особая социальная группа, требующая к себе специальные условия», «лица, не способные самостоятельно удовлетворять свои потребности», «люди, которые не могут сделать что-либо сами. Им требуется помощь», «Люди, которым нужна помощь других людей». Среди респондентов большинство лиц женского пола $(87,5 \%)$.

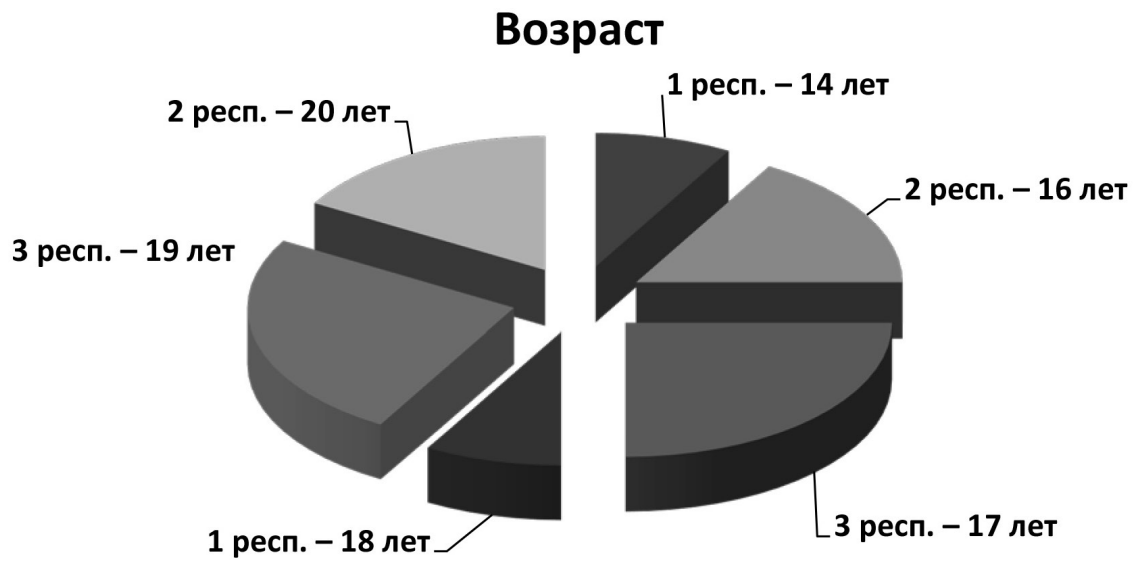

Рисунок 2. Распределение четвертого блока ответов респондентов на вопрос: «Ваше понимание выражения “лица с ограниченными возможностями здоровья”?» (в зависимости от возраста)

В 4,71\% ответов прозвучало понятие полноценности/неполноценности. Примеры формулировок: «Люди, которые не могут полноценно влиться в общество», «человек неполноценен», «человек, который не может полноценно функционировать в обществе с другими людьми», «это лица, которым не все позволено».

Проанализировав ответы на первый вопрос анкеты, можно понять, что уровень готовности нашего молодого поколения учиться вместе с лицами с ограниченными возможностями здоровья не очень высокий.

Респонденты дистанцируются от проблем лиц с ограниченными возможностями здоровья, не включают их в свой круг, рассматривая их как не имеющих отношения к респондентам.

Был задан вопрос: «Если бы в Вашей семье появилось лицо с ограниченными возможностями, что бы Вы сделали?» Варианты ответов на него следующие: «1) ухаживал(-а) бы самостоятельно; 2) нанял(-а) бы сиделку; 3) оформил(-а) бы в спецучреждение; 4) другое (что именно?)». 
Ответы распределились следующим образом: 1) ответили «ухаживал(-а) бы самостоятельно» $82,35 \%$ опрошенных, среди которых $30 \%$ респондентов мужского пола и $70 \%$ респондентов женского пола; 2) ответили «нанял(-а) бы сиделку» $20 \%$ опрошенных, среди которых $29,41 \%$ респондентов мужского пола и 70,59\% респондентов женского пола; 3) выбрали ответ «оформил(-а) бы в спецучреждение» $3,53 \%$ респондентов женского пола (никто из респондентов мужского пола не выбрал этот вариант ответа); 4) ответ «другое» выбрали 4,71\% респондента мужского пола. Их ответы были такими: «1) Пока не имею такого члена семьи, не знаю, видно будет; 2) не дай Бог; 3) убил бы; 4) затрудняюсь ответить - это зависит от болезни (см. рис. 3).

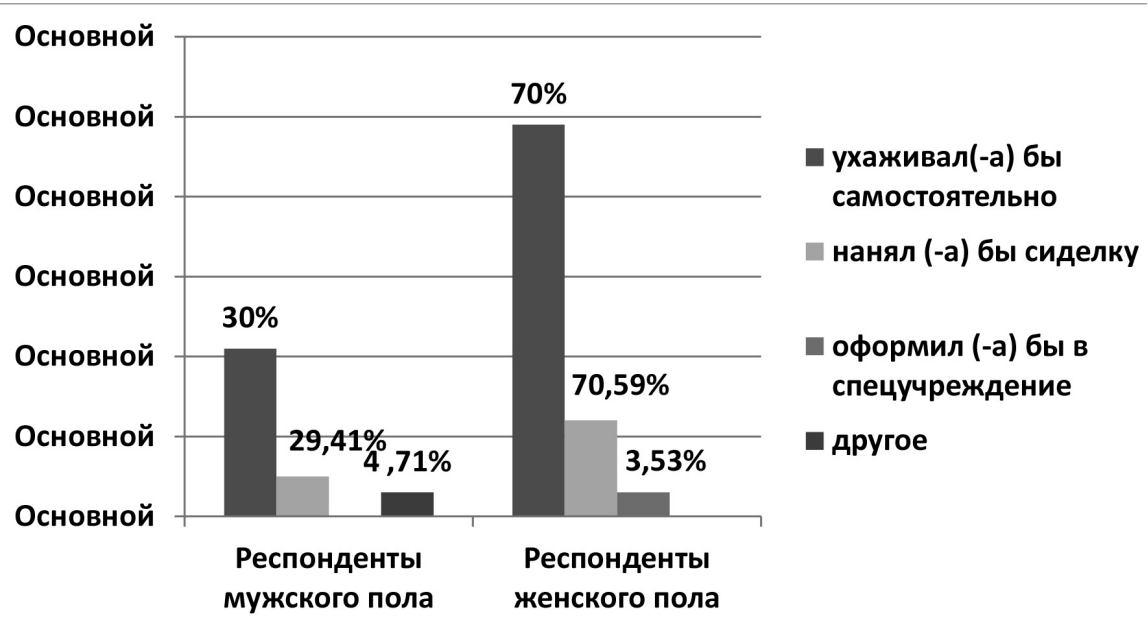

Рисунок 3. Распределение ответов на вопрос: «Если бы в Вашей семье появилось лицо с ограниченными возможностями, что бы Вы сделали?» (в зависимости от половой принадлежности респондентов)

Рассмотрим распределение ответов на этот же вопрос в зависимости от того, кто отвечал, - студенты или школьники.

Ответы распределились следующим образом: 1) ответили «ухаживал(-а) бы самостоятельно» $70 \%$ респондентов - студентов и $30 \%$ респондентов - школьников; 2) ответили «нанял(-а) бы сиделку» 76,47\% респондентов - студентов и $23,53 \%$ респондентов - школьников; 3) выбрали ответ «оформил(-а) бы в спецучреждение» - по одному студенту и школьнику; 4) ответ «другое» выбрали $66,67 \%$ студентов и $33,33 \%$ респондентов - школьников.

Анализ ответов респондентов показал, что как лица мужского пола, так и лица женского пола предпочли бы сами ухаживать за лицами с ограниченными возможностями здоровья, что может свидетельствовать о сформированности чувства ответственности за близких людей, а также о том, что молодежь стремится проявлять заботу о тех, кто нуждается в помощи.

Следующий вопрос: «Если бы Вы оказались в ситуации лица с ограниченными возможностями, что бы Вы предпочли?»

Варианты ответов: «1) чтобы за Вами ухаживали родные; 2) чтобы Вам наняли сиделку; 3 ) чтобы Вас оформили в спецучреждение; 4) другое (что именно?)».

Ответы на этот вопрос распределились следующим образом: 1) первый ответ «чтобы за Вами ухаживали родные» выбрали 69,41\% опрошенных, среди них $22,03 \%$ респондентов мужского пола и $77,97 \%$ респондентов женского пола; 
2) второй ответ «чтобы Вам наняли сиделку» выбрали всего 7,06\%, из них $33,33 \%$ респондентов мужского пола и $66,67 \%$ респондентов женского пола; 3 ) третий ответ «чтобы Вас оформили в спецучреждение» выбрали всего 14,12\% опрошенных, поровну мужского и женского пола; 4) ответ «другое» выбрали всего $11,76 \%$, из них $60 \%$ респондентов мужского пола и $40 \%$ респондентов женского пола. У мужчин были такие ответы: «1) справлялся самостоятельно; 2) суицид; 3) мне все равно». 3 человека не дали никакого ответа.

Респонденты женского пола ответили так: «1) 2 человека затрудняюсь ответить; 2) суицид; 3) нет ответа» (см. рис. 4).

Рассмотрим распределение ответов на этот же вопрос в зависимости от того, кто отвечал, - студенты или школьники.

Ответы распределились следующим образом: 1) первый ответ «чтобы за Вами ухаживали родные» выбрали 69,49\% студентов и $30,51 \%$ школьников; 2) второй ответ «чтобы Вам наняли сиделку» выбрали 66,67\% студентов и 33,33\% школьников; 3) третий ответ «чтобы Вас оформили в спецучреждение» выбрали $83,33 \%$ студентов и 16,67\% школьников; 4) ответ «другое» выбрали 90\% студентов и $10 \%$ школьников из числа выбравших этот вариант ответа.

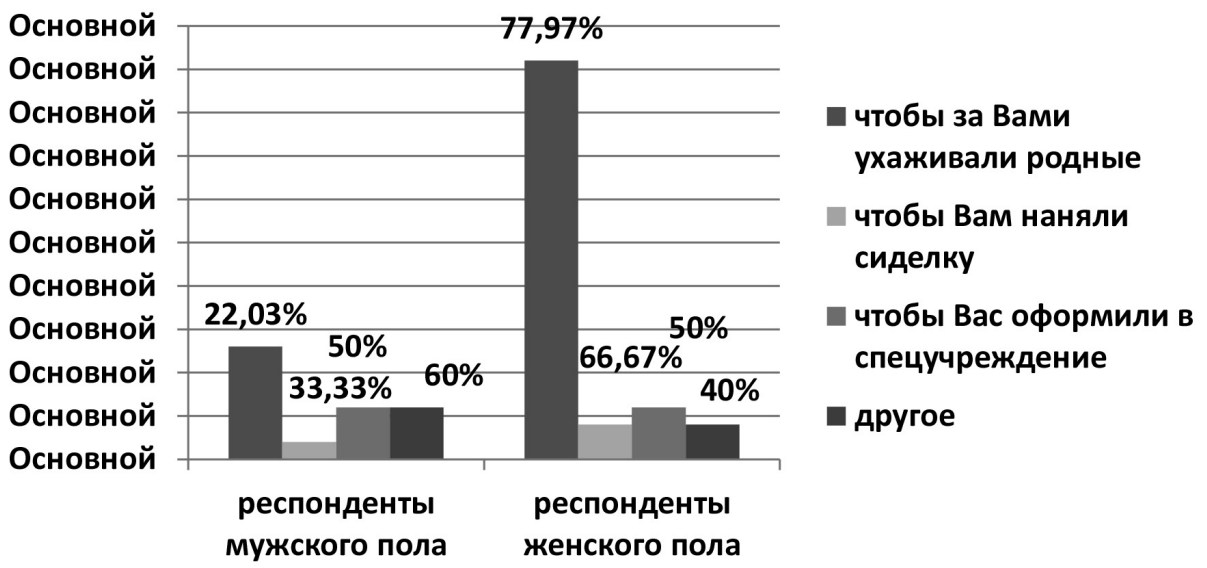

Рисунок 4. Распределение ответов на вопрос: «Если бы Вы оказались в ситуации лица с ограниченными возможностями, что бы Вы предпочли?» (в зависимости от половой принадлежности респондентов)

Следует отметить, что у респондентов наличествует привязанность к родным людям, в своем большинстве они уверены, что родные не оставят их в беде и будут ухаживать, если случится несчастье.

Рассмотрим распределение ответов на вопрос: «Считаете ли Вы эвтаназию выходом из положения, если человек неизлечимо болен?» Варианты ответов были следующими: «да», «нет», «затрудняюсь ответить».

Ответы респондентов распределились следующим образом: ответ «да» выбрали 55,56\% мужчин и 44,44\% женщин, т.е. $31,76 \%$ из 85 опрошенных считают, что эвтаназия является выходом из положения, если человек неизлечимо болен. Таким образом, почти треть респондентов - за прекращение жизни человека, страдающего неизлечимым заболеванием и испытывающего вследствие этого заболевания невыносимые страдания, по его просьбе.

Ответ «нет» выбрали 16,67\% респондентов мужского пола и 83,33\% респондентов женского пола. Вариант «затрудняюсь ответить» выбрали 20,59\% мужчин и $79,41 \%$ женщин (см. рис. 5). 


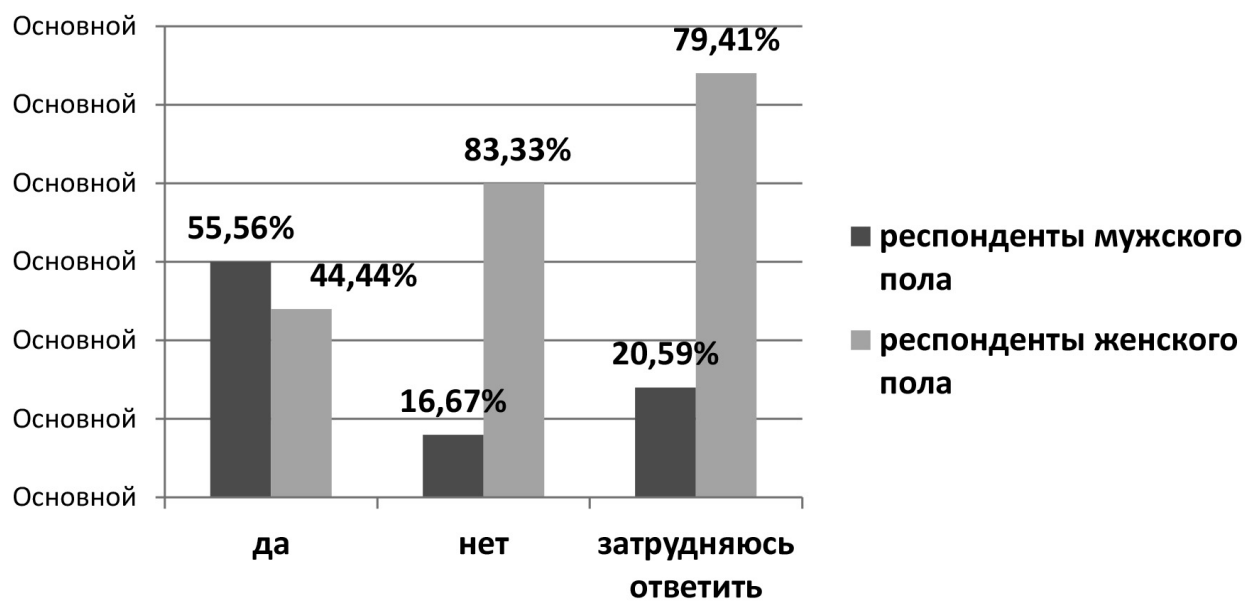

Рисунок 5. Распределение ответов на вопрос: «Считаете ли Вы эвтаназию выходом из положения, если человек неизлечимо болен?» (по полу респондентов)

Далее респондентам был задан вопрос: «Если на предыдущий вопрос ответили “да”, то кто, по-Вашему, должен проводить эвтаназию?»

Ответы распределились следующим образом: 15,29\% респондентов мужского пола дали следующие ответы (приведены все): «1) врачи - 4 ответа; 2) люди, специально обученные для этого, врачи; 3 ) специалист; 4) врач с согласия родных; 5) робот; 6) специально квалифицированный врач; 7 специализированный доктор; 8) медучреждение; 9) сам человек; 10 дипломированный врач».

Как видим, большинство респондентов мужского пола считают, что эвтаназию должны проводить медработники.

$16,47 \%$ респондентов женского пола ответили: «1) врач(-и) - 6 ответов; 2) врач, родные рядом; 3) врачи; люди, понимающие, как это делать правильно; 4) врачи, медработники; 5) ближайший родственник; 6) врачи, имеющие на это законное право; 7) медсестра в присутствии родных; 8) специалисты, врач».

И среди респондентов женского пола большинство склоняется к ответу, что эвтаназию должны проводить медработники.

Нет ответа в анкетах $69,41 \%$ респондентов.

Как представляется, если исходить из анализа ответов респондентов, молодые люди не считают эвтаназию безнравственной и жестокой процедурой. Треть опрошенных лояльно относятся к ее проведению, причем возлагают эту обязанность на медработников.

Можно предположить, что молодежь не готова к тому, чтобы образование в России стало инклюзивным. Ни школьники, ни студенты не понимают проблем лиц с ограниченными возможностями здоровья и не готовы к тому, чтобы эти люди обучались вместе с ними. Поэтому так остро стоит проблема социализации лиц с ограниченными возможностями здоровья и востребовано управление рисками при внедрении инклюзивного образования.

Статья издается на средства договора № 12/21 от 10.03.2021 на выполнение научно-исследовательских работ на тему «Дискурс социальных проблем толерантного отношения молодежи к лицам с ограниченными возможностями здоровья и инвалидам в коммуникативном пространстве». 


\section{Список литературы}

Байдакова Д.М., Киричек П.Н. 2013. Сетевая культура молодежи: границы новой реальности. - Россия в период трансформации: молодежь и вызовы современного общества: сборник трудов конференции. Ярославль: Изд-во МУБиНТ. C. 53-55.

Волнистая М.Г., Мамедов А.К. 2018. Научные коммуникации в системе воспроизводства знаний. - Вышэйшая школа: навукова-метадычны і публіцыстычны чaconic. № 3(125). С. 43-48.

Воронов К.А., Пимахова А.А., Шилина С.А. 2018. Модель работы с детьмиинвалидами: социологические параметры. - Дискурс. № 7(21). С. 97-109.

Гезалов А.А.О., Коркия Э.Д., Мамедов А.К. 2018. Статус и миссия университета в постмодерне. - Век глобализации. № 4(28). С. 152-159.

Голенкова О.В. 2014. Проблемы инклюзивного образования в современном российском обществе. - Актуальные проблемы современного образования: опыт инноваций: материалы научно-практической конференции (заочной) с международным участием. 27-28 ноября 2014 г. Тольятти: НОЦ «Перспектива». C. $112-117$.

Голенкова О.В., Свердлова Г.А. 2021. Региональный опыт модернизации образования. - Дискурс социальных проблем в социокультурном, образовательном, языковом пространстве в период пандемии коронавируса: сборник трудов конференции. Брянск: Изд-во БГУ. С. 381-390.

Киричек П.Н. 2016. Информационная культура в арсенале управленца. Инновационные технологии в управлении: сборник научных статей. М.: ООО «МАКС Пресс». С. 4-10.

Киричек П.Н. 2017. Эрзац-реформа в сфере образования. - Университет в глобальном мире: новый статус и миссии. М.: ООО «МАКС Пресс». С. 632-633.

Киричек П.Н. 2018. Университет в поле социального заказа. - Социальные и психологические проблемы современного образования: сборник трудов конференции. Иркутск: Изд-во ВСИ МВД РФ. С. 183-188.

Ковалева Е.Л., Касацкая В.Н., Ковалева А.В. 2019. Вопросы качества жизни и здоровья в радиационно загрязненных районах. - Социальная динамика населения и устойчивое развитие: сборник тезисов конференции. М.: ООО «МАКС Пресс». С. 151-155.

Ковалева Е.Л., Сычева Е.Ю. 2019. Лица с ограниченными возможностями здоровья: отношение к ним со стороны молодежи. - Дискурс. № 12(38). С. 124133.

Лифанова Т.Е., Сычева Е.Ю. 2019. Социологическое исследование отношения молодежи к лицам с ограниченными возможностями. - Дискурс. № 12(38). С. 134-145.

Мамедов А.К. 2016. Проблема оснований социального знания (полемические заметки). - Экономика. Социология. Право. № 3(3). С. 68-80.

Мамедов А.К. 2018. Научное знание: классическое наследие и мода. Экономика. Социология. Право. № 1(9). С. 91-100.

Мамедов А.К. 2021. Парадигма нового образования в период пандемии: методология и тренды. - Дискурс социальных проблем в социокультурном, образовательном, языковом пространстве в период пандемии коронавируса: сборник трудов конференции. Брянск: Изд-во БГУ. С. 414-421.

Сычева Е.Ю., Белова К.О. 2019. Социологическое исследование: благоприятность среды для жизни лиц с ограниченными возможностями. - Дискурс. № 11(37). С. 112-124.

Шилина С.А., Федорова К.И. 2019. Инклюзивное образование в России как 
одна из форм социализации лиц с ограниченными возможностями. - Дискурс. № 10(36). С. 45-56.

Шилина С.А., Боброва С.А., Лученинова Е.С. 2019. Формирование коммуникативной культуры в процессе внедрения инклюзивного образования в России. - Высшее образование для ХХІ века: роль гуманитарного образования в контексте технологических и социокультурных изменений: сборник трудов конференции. М.: Изд-во Московского гуманитарного университета. С. 226-234.

Шилина С.А., Зайцева В.В., Орлов Г.И., Прудников Е.Е., Корнюшин И.А. 2021. Дискурс социальных проблем в образовательном пространстве: опыт выпускников общеобразовательных школ города Брянска в период пандемии коронавируса. - Дискурс социальных проблем в социокультурном, образовательном, языковом пространстве в период пандемии коронавируса: сборник трудов конференции. Брянск: Изд-во БГУ. С. 400-408.

MELNIKOV Sergei Leonidovich, Cand.Sci. (Ped.), Professor at the Bryansk State Academician I.G. Petrovsky University (14 Bezhitskaya St, Bryansk, Russia, 241023)

LIFANOVA Tatyana Evgen'evna, Cand.Sci. (Ped.), Associate Professor of the Chair of Sociology and Social Work, Bryansk State Academician I.G. Petrovsky University (14 Bezhitskaya St, Bryansk, Russia, 241023)

SHILINA Svetlana Aleksandrovna, Dr.Sci. (Soc.), Professor of the Chair of Sociology and Social Work, Bryansk State Academician I.G. Petrovsky University (14 Bezhitskaya St, Bryansk, Russia, 241023; supershili2012@yandex.ru)

\title{
RISK MANAGEMENT OF INCLUSIVE EDUCATION
}

\begin{abstract}
The article deals with topical issues of the attitude of young people (students and high school students) to people with disabilities. The authors present the results of a sociological study, which revealed reference points existing when implementing inclusive education in Russia. The authors analyze the issues that need to be solved in order to attain loyalty towards persons with disabilities in modern society. Much depends on management decisions to ensure an accessible environment for this category of citizens. In order to avoid risks in the implementation of inclusive education, joint efforts of society and the state are necessary. Social policy should be aimed at facilitating the entry of persons with disabilities into society. We need measures that create a tolerant attitude towards disabled people, as well as favorable conditions for their existence in the urban environment of modern megacities. That is undoubtedly an urgent problem of our state.

Keywords: inclusive education, people with disabilities, disabled people, risks, management, COVID-19, society
\end{abstract}

